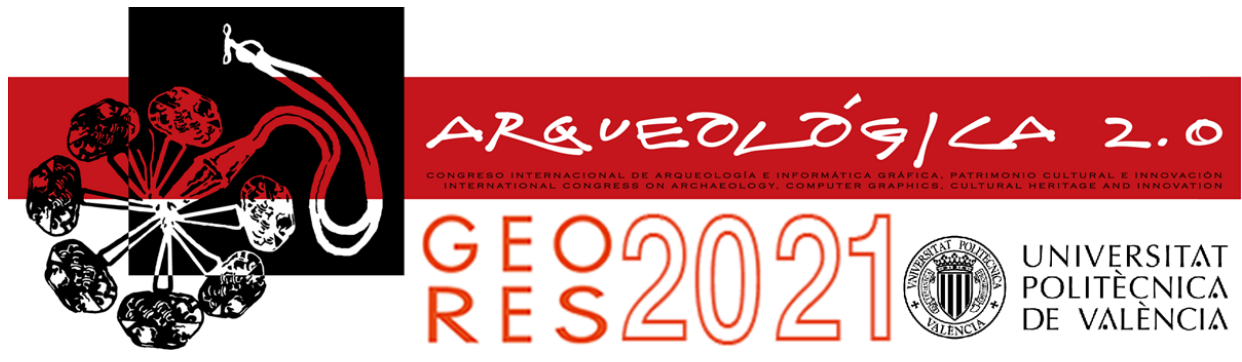

Proceedings of the joint international event $9^{\text {th }}$ ARQUEOLÓGICA

$2.0 \& 3^{\text {rd }}$ GEORES

Valencia (Spain).

26-28 April 2021

\title{
AN INTEGRATED APPROACH AIMED AT THE PROTECTION OF CULTURAL HERITAGE: FROM THE GEOMATIC SURVEY TO HBIM AND AR REPRESENTATION OF VILLA PISANI (STRA, ITALY)
}

\author{
Michele Monego ${ }^{a, b}$, Simone Maiolic ${ }^{c}$ Matteo Salvalaggio ${ }^{a,{ }^{*}}$ \\ a Department of Cultural Heritage, University of Padova, Piazza Capitaniato 7, 35139 Padova, Italy. michele.monego@unipd.it; \\ matteo.salvalaggio@unipd.it \\ b Department of Civil, Environmental and Architectural Engineering, Via Marzolo 9, 35131 Padova, Italy. michele.monego@unipd.it \\ c School of Engineering, University of Padova, Via Marzolo 9, Padova 35131, Italy. simone.maioli@studenti.unipd.it
}

\begin{abstract}
:
The topic of Cultural Heritage preservation has gained increasing attention during the last decades. The protection of such complex and delicate manufactures require the intervention of experts from a different field (e.g. archaeology, restoration, survey, 3D modeller, structural engineering, architecture), addressed towards an integrated and multidisciplinary scientific approach. Recently, technology advancements have involved many scientific disciplines, affecting both investigation tools and data computing. In this paper, an approach aimed at assessing the health status and preserving a heritage building is presented and applied to a case study, exploiting the most effective tools nowadays available. Based on the so-called knowledge path, the study started from the analysis of historical data, through the collection of in-situ measures and towards the construction of a 3D digital model where the information is stored. In particular, a set of images taken by drone and processed by the photogrammetric technique of Structure from Motion, were used to produce detailed point clouds, mesh model, DEM and orthophotos that collect accurate geometrical documentation, useful to analyse the conservation status and the crack pattern. Based on the detailed model from geomatic survey and drawings, a Heritage Building Information Modelling (HBIM) database was collected with the possibility of managing historical, geometric, structural and health status information. In the end, the study focused on the availability of the information collected for non-professional users or professionals from different fields, who do not have access to data kept in a commercial database. Partly, this resulted in the elaboration of the augmented reality (AR) model, accessible by common mobile applications. The case study is Villa Pisani in Stra (Venice, Italy), a well-known example of Venetian villa built in the XVIII century which hosted many protagonists of European contemporary history.
\end{abstract}

Keywords: cultural heritage, health monitoring, geomatic survey, HBIM, drone, augmented reality

\section{Introduction}

The protection of Cultural and Architectural Heritage is a mission that assumes prominent importance in a country such as Italy, with plenty of extraordinary buildings and manufactures. Among these is Villa Pisani in Stra (Venice), an XVIII-century Venetian villa.

The study presented in this paper is moved by the necessity to detect the health and conservation status of Villa Pisani, but not limited to it. Since the building is part of the architectural heritage it is also protected by specific conservation laws, which rule the investigations and survey procedure. The appearance of the building cannot be altered, and destructive tests are neglected. These limits became the occasion to apply an integrated approach, based on state-of-art geomatic survey techniques and 3D modelling methods.
The main aims of the study here presented are:

- Detection of the conservation status of Villa Pisani;

- Validation of a multidisciplinary approach, based on the integration of survey data with historical information and the recollection into a 3D HBIM;

- Availability and accesibility of the HBIM database to a wide range of professional and non-professional users, taking advantage of opensource tools.

\subsection{Villa Pisani}

Villa Pisani in Stra, Italy (Fig. 1) is an extraordinary example of a Venetian villa, which aroused in the XVIII

*Corresponding Author: Matteo Salvalaggio, matteo.salvalaggio@unipd.it 
century as a summer residence for the wealthy Pisani family.

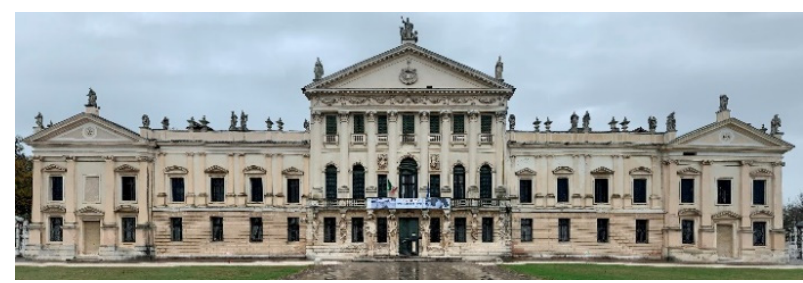

Figure 1: Main façade of Villa Pisani (Stra, Italy).

Francesco Maria Preti was the architect of the building project, whose layout has remained unchanged during centuries (Favaro Fabris, 1954). The structure is inscribed in a square $80 \times 55 \mathrm{~m}$, composed of thick clay brick masonry walls with timber floors and roof. A magnificent garden was designed adjacent to it, with annexes and outbuildings for leisure (e.g. greenhouse, guardian house, labyrinth).

In 1806, the French occupation of Venice resulted in the weakening of Pisani family, which sold the complex to Napoleon for the use of the viceroy Eugene of Beauharnais, until 1815. In those years, some structural arrangements were done, as the creation of two apartments with the introduction of new floors and bathroom, including the well-known Napoleon bathtub.

Passed through the Austrian occupancy of the Venetian region, the villa remains basically unchanged. After the end of foreign domination in 1866, the residential use of Villa Pisani ended too.

In the first years of the $X X$ century, the University of Padova managed the complex as Hydro technology Institute and introduced the huge water basin in the garden (Ferrari \& Rallo, 2011). After the emergency use as a military hospital during the First World War and a general abandonment, in the 80 s a renewed interest towards the complex aroused, with the restoration of the Tiepolo fresco in the magnificent ballroom (Rallo \& Monti, 2000).

Nowadays, the Villa Pisani system is a National Museum itself, which need to be protected and maintained through visitor's fruition and the frequent monitoring of its structures health.

\section{Materials and methods}

The methodology followed the well-known knowledge path (Binda, Cardani, Saisi, Modena, \& Valluzzi, 2004; Valluzzi et al., 2019; EN 1998-3, 2005), which comprehends the historical analysis, the collection of onsite data, the critical interpretation of decay status and crack pattern, the management and analysis of results. The data could be implemented later in the structural assessment of the building, similarly to the procedure reported in Sbrogiò, Salvalaggio, \& Valluzzi (2020).

Once the historical phases have been reconstructed, the in-situ operations have been addressed to the collection of geometrical, architectural and conservation data.

The data presented in this paper have been collected through totally non-destructive techniques, which involved direct measures of objects, photogrammetry reconstructions through professional cameras and the collection of aerial images through drone flights. This permitted to generate a point cloud of the building external surfaces (i.e. façades and roofs).

The processing of the data brought to the validation of the geometrical survey, the creation of a photographic survey and the editing of a critical survey, made through a detailed analysis of the non-structural materials deterioration processes and the mapping of the decay status (i.e. masonry cracks, wall inclination, roof depressions) which affects the structures.

This amount of data has been following implemented in a 3D HBIM model into the Autodesk Revit environment, where structural, geometric and conservation information are managed.

In the end, the accessibility issue of commercial software from non-specialized users has been overcome through the creation of an AR model in the Unity environment, accessible through a mobile application within Android and iOS operating systems.

In the following, the main materials and technologies adopted are described.

\subsection{Geomatic survey}

The improvement of the architectural knowledge about Villa Pisani was supported, in the first phase, by a campaign of geomatic survey.

Geomatic techniques, in the last years, have shown a crucial increasing in efficiency due to the development of sensors and software that improve the quality of the data and the user-friendliness of the devices. Thanks to that, in many cases the main aims can be focused on producing the proper and most adequate documentation oriented by multidisciplinary requirements (Sammartano \& Spanò, 2017).

In this case, the choice of a "light" approach seemed to be an adequate solution in an optic of non-invasive presence in a particular protected site and considering the relation between time of surveying and obtained results (Carraro et al., 2019). An aerial photogrammetric survey with a lightweight drone (Fig. 2a) and a set of GNSS measurements were chosen for the imagery acquisition and the measurements of the control points. The main aim of the survey was the coverage of the roof in order to produce a detailed orthophoto, useful in the visual detection of roof degradation. This inspection through the orthophoto, for instance, could support the Superintendence in the monitoring of damages in the roof tiles.

For scaling and georeferencing the survey 20 planar targets (Fig. 2b) were positioned on the ground around the building and measured by GNSS acquisition with RTK technic. The distribution of the GCPs only on the ground (and not on the façades or roof) represents a clear limit for an optimal control of the resulting model. However, it is not possible to access the roof area with a reasonable safety margin if not with a considerable use of means and time.

It has to be stated that the aero-photogrammetry was primarily aimed at the creation of an orthophoto of the roof and, only later, the good results in the vertical surfaces of the building brought to use the model also in support of HBIM modeling. 
A future flight, focused on the façades and with new GCPs could be a further step in the digital documentation and study of the building. The images were processed by SfM technic using the software Agisoft Metashape while the further data extracted from the models were produced through 3DReshaper and JRC Reconstructor.

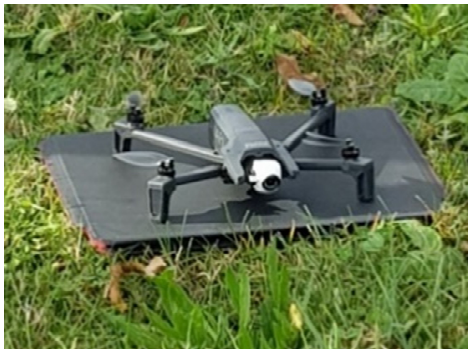

(a)

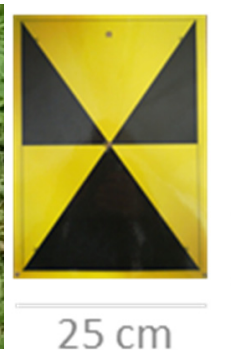

(b)
Figure 2: Aerial photogrammetric survey: a) Parrot Anafi drone; b) control point

\subsection{HBIM approach}

The use of HBIM approach for historical buildings and fields such as AR/VR has not been fully investigated yet. One of the main reasons is the difficulty in representing detailed elements of $\mathrm{CH}$ such as irregular walls, decay phenomena and ancient traces of structures corrupted by time, which require a high level of knowledge of the artefact (Banfi, 2016). For this reason, in particular, HBIM models should become more beneficial for historical buildings as they offer access to both geometric and historical information, allowing to use this information for its maintenance (Chiabrando, Lo Turco, \& Rinaudo, 2017), which a traditional approach cannot offer. The BIM creation process can be differentiated for i) new and ii) existing buildings, due to variation in building information quality, information availability and functionality requirements (Brumana et al., 2020). In the case study, the support of photogrammetry facilitated the HBIM modelling process, making it possible to compare the model with the geometric information of the point cloud. It was possible to update the 2-D geometric survey by a cross-checking procedure with the point cloud, refining, among the others, the dimensions of the façade elements, the inclination of the pitch and the height of the floor. Furthermore, it allowed collecting data about the storeys heights (i.e., to produce geometric sections). Other types of analysis were permitted, such as checking the orthogonality of the perimeter walls or highlighting overhanging elements. From an operational point of view, the process of creating the HBIM model was divided into three phases: i) data collection, ii) processing and iii) integration of the collected data (Fig. 3).

The first step involved the collection of all existing knowledge, studying historical sources, archival documents, drawings, descriptions of the techniques and materials used. The second step consisted in the reelaboration of the collected data with the survey data in order to obtain a reality-based model. By mapping, for example, demolition and new construction parameters on the masonry through the phases, structural functions on the wooden carpentry and decay on the façades. Finally, all the information was implemented in 2-D and 3-D reports, producing the necessary documentation for the scheduled maintenance interventions, as well as carrying out all the essential queries to plan the required actions.

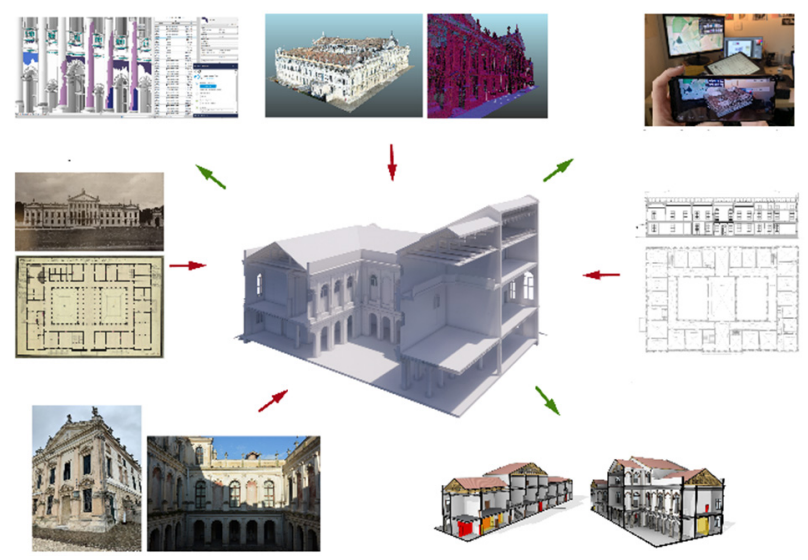

Figure 3: HBIM model input and output.

\subsection{From HBIM to $A R$}

Aiming at the accessibility of the model and the results to professionals and a wider audience, an augmented reality (AR) application for mobile devices was developed. In this way it was made possible to share information about Villa Pisani through graphic visualization, improving the communicative strength of the contents. The application of these innovative tools in the field of cultural heritage and the historical building has to be considered a fundamental opportunity (Cabrelles, Blanco-Pons, Carrión-Ruiz, \& Lerma, 2018). The use of an application improves the user experience because virtual elements are superimposed based on a real world, enriching it with information that is not easily available, and leading to virtual involvement.

This was possible thanks to the union of the BIM world with object-oriented programming and software like Unity. Importing a BIM model by fbx format into Unity involves the recognition of the geometry through the name of the type / family (entered in the modelling environment) and the recognition of the ID linked to each instance. This dependency has facilitated the app creation process (Lai, Hu, Cui, Sun, \& Dai, 2018).

Vuforia was used for the development of the apps, an advanced AR building engine that inside Unity provides an intuitive platform for creating augmented reality apps for Android and iOS platforms (Fig. 4). In practice, the Augmented Reality (AR) application permits, through the camera of a compatible device and the recognition of a predetermined target, to view the model of the Villa in correspondence of the target surface. In addition to visualization, the app makes possible to interact with the model.

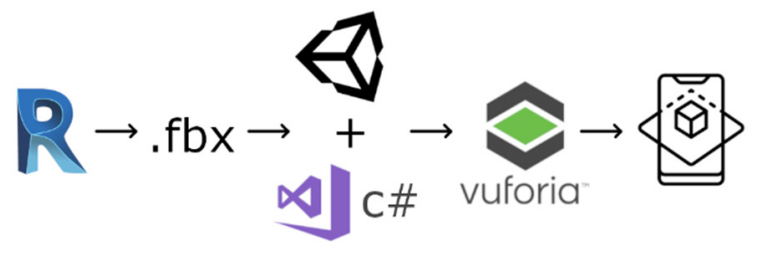

Figure 4: AR app development process. 


\section{Results and discussion}

In this section, the results of the work are presented and discussed.

\subsection{D model from survey}

A set of 782 aerial images was taken with a Parrot Anafi drone (Table 1), using inclinations of $90^{\circ}$ and $70^{\circ}$ in 3 different flight plans, at a mean altitude from the ground of $33 \mathrm{~m}$ and with a resulting Ground Sample Distance (GSD) of $6 \mathrm{~mm}$.

Table 1: Technical specifications on aerial imagery acquisition with Parrot Anafi drone.

\begin{tabular}{c|c} 
Setting & Value \\
\hline Sensor & $1 / 2.4 " 21$ MP CMOS Sony \\
Image size & $5344 \times 4016$ pix \\
Fly height (mean) & $33 \mathrm{~m}$ \\
GSD (mean) & $6 \mathrm{~mm}$
\end{tabular}

The processing of the 782 images started with the aerotriangulation phase and brought to the extraction of a sparse cloud consisting of 747,631 tie points (Fig. 5a). A more specific area around the building was selected for the further processing that produced a dense cloud of $114,948,462$ points and a triangular mesh model of $26,183,087$ (Fig. 5b). The high density of points is a necessary feature to get an adequate model, which can be used for the detection, for example, of small anomalies in the roof surface. In order to validate the geometrical accuracy of the result, a set of GCP (Ground Control Points) have been measured and introduced in the processing phase. These targets provided the georeferencing of the data and the error evaluation. The coordinate reference system is the Italian national projection system Gauss-Boaga (west fuse), classified with code EPSG: 3003 - Monte Mario Italy (zone 1).
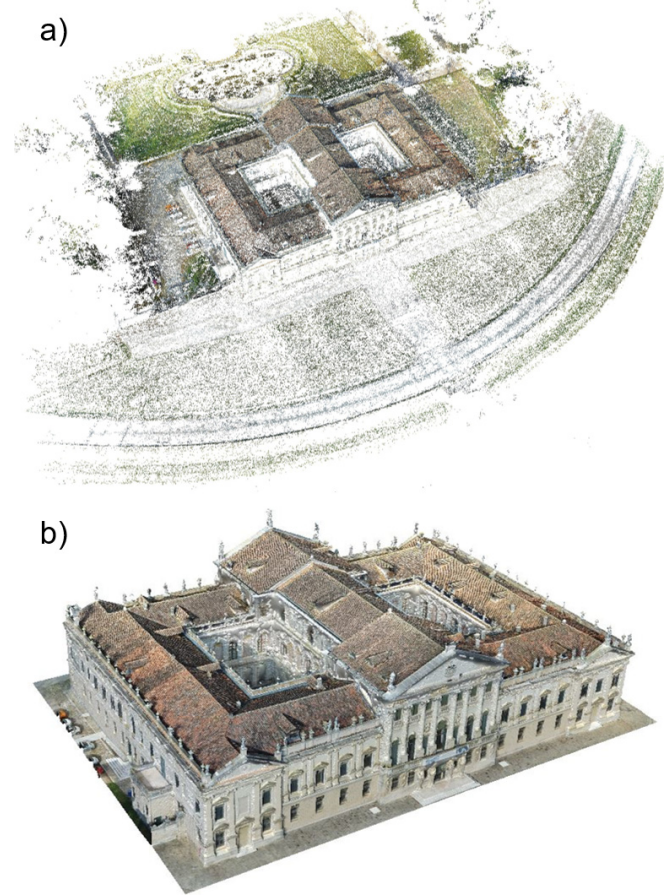

Figure 5: Processing of images (Agisoft Metashape): a) Sparse cloud of Villa Pisani from SfM; b) Textured mesh surface model.
The choice of this reference system is motivated by the need for uniformity with the existing archival data.

In this case the GCP are divided in Control Points, the targets that were used also for scaling and georeferencing the model, and Check Points that are the markers used only for the error verification. The RMSE values are shown in Table 2 while the graphical representation can be observed in Figure 6.

Table 2: Control points and check points RMSE.

\begin{tabular}{c|c|c} 
Setting & Control Points & Check Points \\
\hline Number of points & 13 & 3 \\
X error $(\mathrm{cm})$ & 1.0 & 1.3 \\
Y error $(\mathrm{cm})$ & 1.1 & 1.9 \\
Z error $(\mathrm{cm})$ & 2.0 & 0.3 \\
XY error $(\mathrm{cm})$ & 1.5 & 2.3 \\
Total error $(\mathrm{cm})$ & 2.5 & 2.3
\end{tabular}

Considering the objectives and the methodology, the global accuracy of the survey is good, and the model can be used as a reliable base of data both for BIM and architectural or structural analysis.

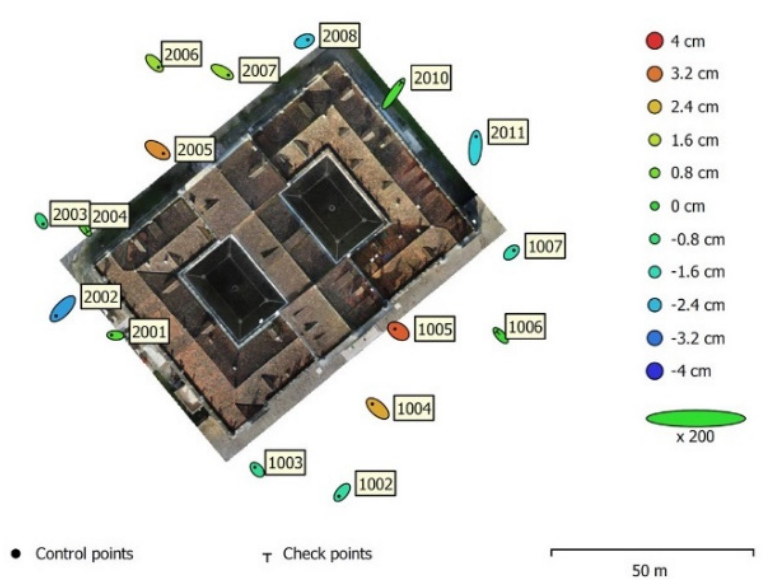

Figure 6: GCP locations and error estimates.

A further product extracted from the 3D model was a DEM $(1.2 \mathrm{~cm} / \mathrm{pix})$ that allowed some observations focused on the health status of the roof coverage. While the inspection of the conservation status of the tiles could be done through a visual check of the single high-resolution images taken by the drone, a deeper view of the structure was made possible by morphological analysis. First, a height map was created for the DEM searching for a customized colour scale with a customized palette that permits highlighting the geometry of the roof pitches as shown in Figure $7 a$.

Besides this, a set of contour lines with interval of $10 \mathrm{~cm}$ and $1 \mathrm{~m}$ was produced from the DEM and so the capacity of detecting the morphological anomalies was improved (Fig. 7b). In some parts of the roof small differences in the continuity of the colour or the lines were evident and could be considered as surface displacement caused by underlying deformations. Of course, the age, the materials and a physiological adjustment of the structure must be considered as factors in the global evaluations. The area that was identified as possibly subject to 
problems will be directly investigated with site inspections and targeted diagnostics on the roof beam structure.
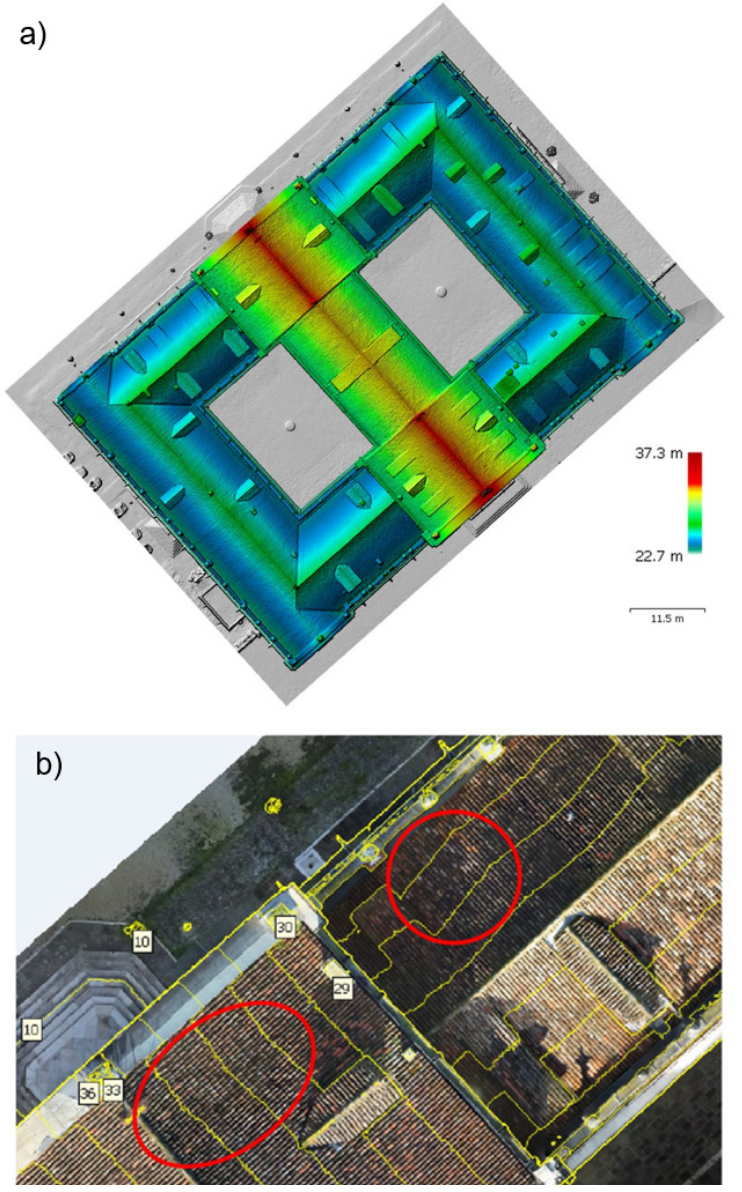

Figure 7: Products extracted from the 3D model: a) DEM with height colour scale of the roof part; b) Orthophoto with contour lines (interval of $1 \mathrm{~m}$ ) with an example of two anomalies that could imply more detailed in-site inspections.

\subsection{Conservation status analysis}

The large amount of data elaborated provided the base for the performance of a detailed analysis of Villa Pisani external surfaces. First, a map of the decay phenomena and crack patterns was prepared, which revealed the effects of weathering. Plaster and stone covers, in some cases, are powdered leaving the underneath structural masonry vulnerable to deterioration (Fig. 8a), especially near the foundations. Some deposits of vegetal and inorganic patina were detected, as well as black spot and pouring, due to stagnating water and humidity.

Furthermore, the processing of on-site data allowed to perform a primary detection of the displacements and strains occurred and occurring in the main structural parts (e.g. walls and roofs). In particular, the analysis of Figure 7 permitted to assess the health of timber roof systems, made of truss beams and purlins. The anomalies detected provided the focus of the investigation plan on that parts, whose timber components are being investigated (Fig. $8 b)$.

\subsection{HBIM and data enrichment}

The digital reconstruction of the artefact, through its modelling, made possible to integrate the data relate to historical variations using the "phases" tool of the Revit software. The operation carried out was to implement the information about variations undergone over time associating a date with it, and subsequently creating a historical phase within the software for each of the dates with details about the construction and/or demolition of the architectural elements. In this way, 8 historical phases from the original state to the current one have been obtained. The last step was to associate each element with its construction or demolition phase, then extrapolate views for each comparative date where the elements are displayed in red (built) or yellow (demolished).

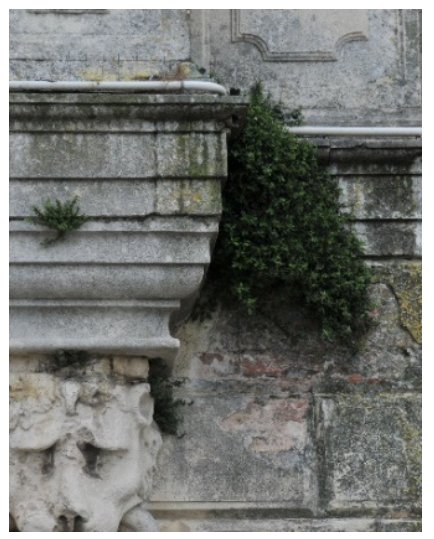

(a)

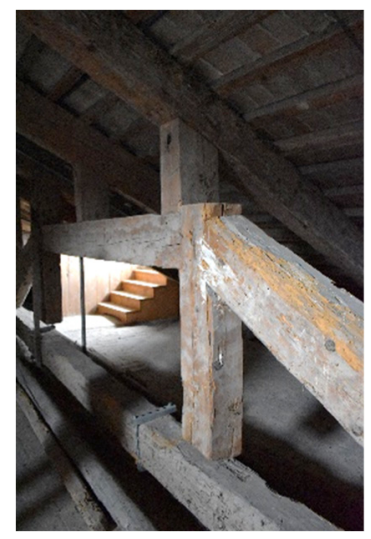

(b)
Figure 8: Detailed analysis of Villa Pisani external surfaces: a) Southern façade decay detail; b) roof system detail.

Again, referring to the information provided by the Superintendence of Cultural Heritage of the Veneto, it was possible to identify both the structural types of floors and roofs and previous consolidation interventions, validated by the historical and documentary information found. Once all this information has been entered into the digital model, it was possible to classify the different elements by type, size and material, finally extrapolating the schedules that uniquely identified the different types of structural system, facilitating identification and possible calculation (Fig. 9).

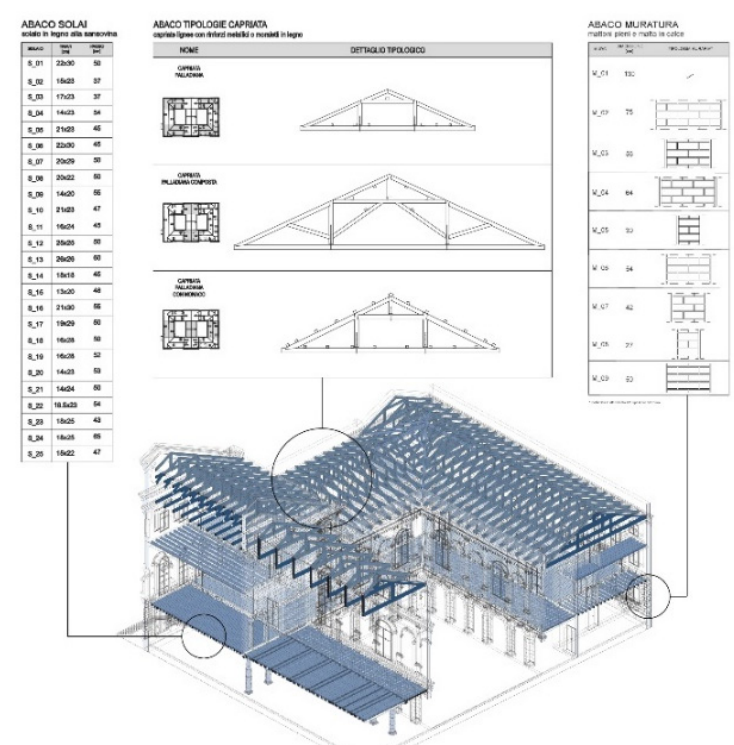

Figure 9: HBIM structural 3D view with related schemes. 
In the field of BIM modelling, however, being able to effectively mapping degradation required an important research and application effort. The objectives set included the geometric representation of degradation in the model, the position and, above all, the quantification and classification of the degradation phenomena.

In the Revit environment, it is not easy to manage these operations and thus it was necessary to use the tool Dynamo visual programming, integrated within the program. First, through the observation of the building 3$\mathrm{D}$ configuration and the photographic documentation, the state of conservation was investigated, detecting the different forms of degradation and mapping them into $\mathrm{CAD}$ environment as closed areas. Following, the areas were imported into the Revit software. These were converted into real BIM objects thanks to the use of a script developed in Dynamo (Fig. 10). The script first proceeds by asking the user to select the surface on which the degrade should be placed and the thickness to assign to it. After that, it is necessary to select the closed areas (consisting of model lines) that correspond to a specific type of deterioration. Given these input values, the selected area is extruded until its intersection with the surface. This creates a geometry and a subsequent generic family.

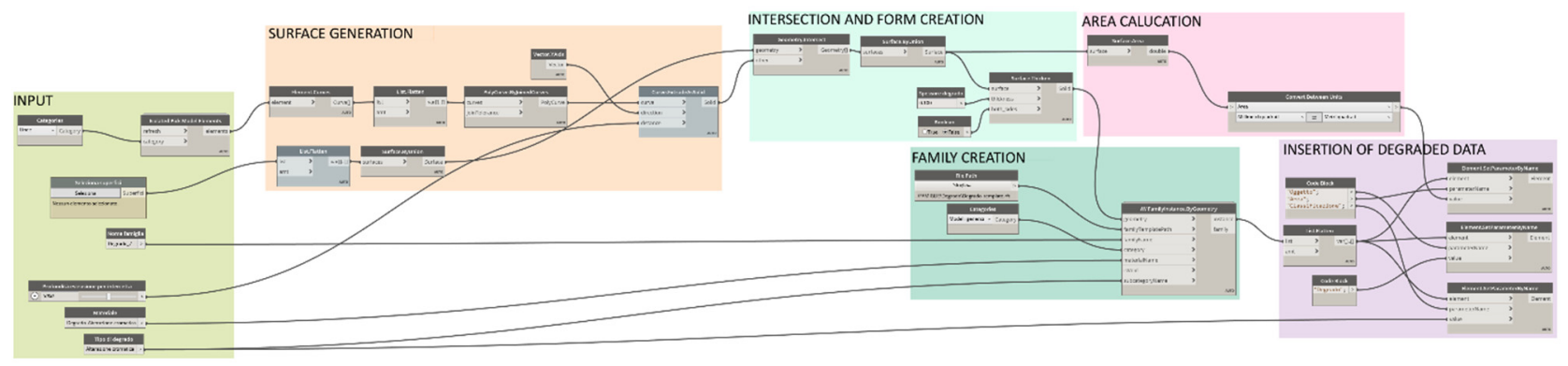

Figure 10: Dynamo code for the execution of the degradation mapping in Revit.

Once the generated geometry has been inserted into the model, other operations are performed to insert further data, as follows:

- Type of degradation (defined by the user as input);

- Fill according to Raccomandazioni NorMaL 1/88 (CNR-ICR, 1990) and UNI 11182 (2006) (application of a material to the geometry created);

- $\quad$ Surface area (calculated using the same script).

Once the degradation modelling and related information have been obtained, it will be possible to create the schedule including all the information necessary for adequate description and quantification (Fig. 11).

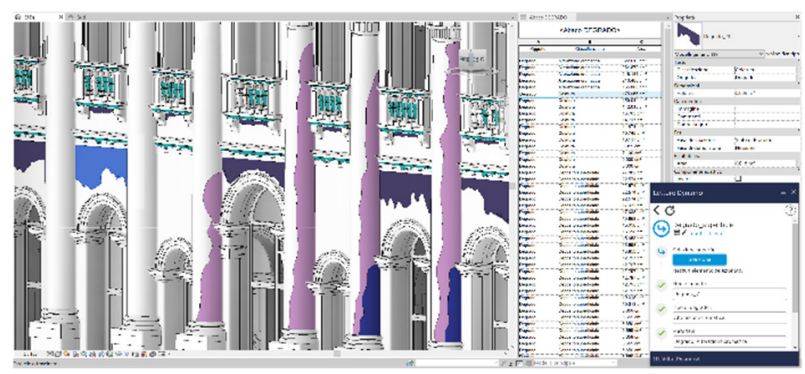

Figure 11: Mapped decay in the Revit environment.

\section{4. $\quad$ AR for information sharing}

The ability to recognize and track arbitrary images is a powerful boost to AR applications as it avoids the requirement of creating and distributing custom markers paired with specific apps. In this case, the plan of the villa first floor is the target to be pointed through the mobile camera, in order to make its use more intuitive. The interaction with the model by means of the application occurs through virtual buttons. It is possible to change the visualization in order to select and highlight separately the 3D architectural or structural components (Fig. 12). In this way, professionals in the field such as architects and engineers can use the app as an open-source dissemination tool and integration to paper documents.

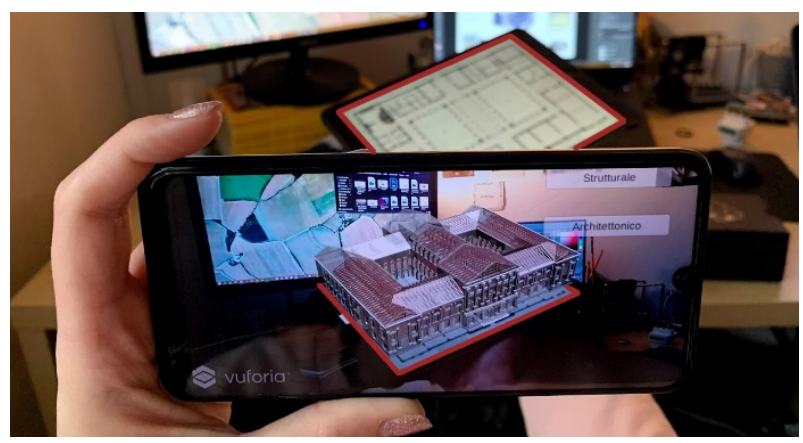

Figure 12: A view of the structural model through the AR app.

Actually, its use is not bound to any software or specific skills. One can use the app to search for spatial information through the phone. Additionally, museum users gain virtual access to parts of the villa they would not otherwise be able to, and browse through the building in an intuitive and fun way. At last, aiming at advertising the site among cultural heritage media, the app can be shared through Superintendence of Cultural Heritage to cultural institutions concerned.

\section{Conclusions}

The reported study shows a part of the results that the application of a multidisciplinary approach could produce in the field of the conservation of cultural and architectural heritage.

Two main lines, aimed at the protection of the building, were followed. The first consists on the assessment of the health of the structure through survey and site activities. 
The second line regards the collection, management and analysis of the data, in an optic of sharing information to make them available for consulting by professional and non-professional users.

Furthermore, the promotion and stimulation of tourism, to keep Villa Pisani a territory monument worthy of investment, come also from the spreading of historical and architectural knowledge through common usage tools.

Besides, the application of well-known methodologies and the extraction of reliable data is important to make this data useful and productive, not only as pure documentation.

Fruitful dialogue between the disciplines was fundamental to choose the better strategies of intervention in the site. In this way, the integration of competences of geomatics, architecture, engineering and 3D modelling provided a workflow that aimed to be as efficient as possible.

Geomatic methods such as SfM and GNSS provided an accurate set of $3 D$ data in form of point clouds, mesh models, DEM and orthophotos. These constituted solid metric support for analysis of the conservation status, above all in a not accessible area like the roof.

An HBIM model, based on drawings and survey data, collected all the information, and permits the querying and the management of the different types of data. It could be consulted by professional operators, both in the technical and cultural field, with the common aim of $\mathrm{CH}$ preservation and valorisation.
At last, an AR model was developed as an example of possible fruition for common users, trying to disseminate the knowledge of the historical building and promote tourism, also through easy tools within everyone's reach.

\section{Acknowledgements}

The work was carried out in the frame of a multidisciplinary collaboration between the Department of Cultural Heritage - dBC and the Department of Civil, Environmental and Architectural Engineering - DICEA of the University of Padova under the leading of Prof. Maria Rosa Valluzzi.

The authors wish to thank the A.Y. 2019/20 students of the Restoration course in Architectural Engineering (Marta Angeletti, Filippo Baldan, Marco Baratto, Jorge Garcia Hernanze, Martina Giorio, Arianna Mazzocchin, Giorgia Saltarin, Martino Zadra) and the teaching assistants for the support in the collection and elaboration of on-site data.

The authors would like also to thank Prof. Vladimiro Achilli for the availability of instruments and software of the Laboratory of Survey and Geomatics - LRG and Prof. Andrea Menin for the GNSS survey.

The authors wish to thank Arch. Loretta Zega, Director of the National Museum of Villa Pisani, for the possibility to access and study this magnificent building.

\section{References}

Banfi, F. (2016). Building Information Modelling-A novel parametric modeling approach based on 3D surveys ofhistoric architecture. In Euro-Mediterranean Conference, 116-127. Cham: Springer. https://doi.org/10.1007/978-3-31948496-9_10

Binda, L., Cardani, G., Saisi, A., Modena, C., \& Valluzzi, M. R. (2004). Multilevel approach to the analysis of the historical buildings: application to four centers in seismic area finalised to the evaluation of the repair and strengthened techniques. In: Proceedings of the 13th International Brick and Block Masonry Conference, Amsterdam, July 4-7 2004.

Brumana, R., Oreni, D., Barazzetti, L., Cuca, B., Previtali, M., \& Banfi, F. (2020). Survey and scan to BIM model for the knowledge of built heritage and the management of conservation activities. Digital Transformation of the Design, Construction and Management Processes of the Built Environment, 391-400, Springer International Publishing. https://doi.org/10.1007/978-3-030-33570-0_35

Cabrelles, M., Blanco-Pons, S., Carrión-Ruiz, B., \& Lerma, J. L. (2018). From multispectral 3D recording and documentation to development of mobile apps for dissemination of cultural heritage. In T. Levy, I. Jones (Eds.), Cyber-Archaeology and Grand Narratives, 67-90. Cham: Springer. https://doi.org/10.1007/978-3-319-65693-9_5

Carraro, F., Monego, M., Callegaro, C., Mazzariol, A., Perticarini, M., Menin, A., Achilli V., Bonetto J., \& Giordano, A. (2019). The 3D survey of the roman bridge of San Lorenzo in Padova (Italy): a comparison between SfM and TLS methodologies applied to the arch structure. Int. Arch. Photogramm. Remote Sens. Spatial Inf. Sci., XLII-2/W15, 255-262. https://doi.org/10.5194/isprs-archives-XLII-2-W15-255-2019

Chiabrando, F., Lo Turco, M., \& Rinaudo, F. (2017). Modeling the decay in an HBIM starting from 3D point clouds. A followed approach for cultural heritage knowledge. The International Archives of the Photogrammetry, Remote Sensing and Spatial Information Sciences, XLII-2/W5, 605-612. https://doi.org/10.5194/isprs-archives-XLII-2-W5$605-2017$

CNR-ICR. (1990). Raccomandazioni NorMaL - 1/88. Alterazioni macroscopiche dei materiali lapidei: lessico.

EN 1998-3. (2005). Eurocode 8: Design of structures or earthquake resistance, Part 3: Strengthening and repair of buildings.

Favaro Fabris, M. (1954). L'architetto Francesco Maria Preti di Castelfranco Veneto 1701-1774. Treviso, Italy: Tipografia Editrice Trevigiana 
Ferrari, S., \& Rallo, G. (2011). Venezia, Italia. Villa Pisani da villeggiatura di corte a museo degli Italiani. Venice, Italy: Medoacus Edizioni.

Lai, Z., Hu, Y. C., Cui, Y., Sun, L., \& Dai, N. (2017). Furion: Engineering high-quality immersive virtual reality on today's mobile devices. Proceedings of the 23rd Annual International Conference on Mobile Computing and Networking, 409-421. Snowbird, Utah, USA. https://doi.org/10.1145/3117811.3117815

Rallo , G., \& Monti, G. (2000). Opere di restauro e valorizzazione di Villa Pisani a Stra. Padova, Italy: II Prato.

Sammartano, G., \& Spanò, A. (2017). High scale 3d modelling and orthophoto of curved masonries for a multipurpose representation, analysis and assessment. The International Archives of the Photogrammetry, Remote Sensing and Spatial Information Sciences, XLII-5/W1, 245-252. https://doi.org/10.5194/isprs-archives-XLII-5-W1-245-2017

Sbrogiò, L., Salvalaggio, M., \& Valluzzi, M. R. (2020). Local mechanism analysis in unreinforced masonry buildings according to a new procedure based on floor spectra evaluation. In J. Kubica, A. Kwiecien \& L. Bednarz (Eds.), Brick and Block Masonry - From Historical to Sustainable Masonry, Proceedings of the 17th International Brick/Block Masonry Conference, July 5-8, 2020, Kraków, Poland. https://doi.org/10.1201/9781003098508.

UNI 11182. (2006). Beni culturali -Materiali lapidei naturali ed artificiali -Descrizione della forma di alterazione -Termini e definizioni.

Valluzzi, M.R., Marson, C., Taffarel, S., Salvalaggio, M., Deiana, R., \& Boaga, J. (2019). Structural investigations and modelling of seismic behaviour on ruins in the monumental area of Hierapolis of Phrygia. In: Aguilar R., Torrealva D., Moreira S., Pando M.A., Ramos L.F. (eds) Structural Analysis of Historical Constructions. An Interdisciplinary Approach. RILEM Bookseries, 18, 1849-1857, Springer, Cham. https://doi.org/10.1007/978-3-319-99441-3_198. 